\title{
En los comienzos de la filosofía cristiana: La actitud de los escritores eclesiásticos y de los gnósticos ante la filosofía
}

\section{INTRODUCCIÓN}

Uno de los méritos reconocidos de la formidable obra de investigación de Antonio Orbe, el patrólogo jesuita español que durante más de cuarenta años ha sido el Profesor de Patrística de la Pontificia Università Gregoriana de Roma (1), ha sido demostrar que muchos de los temas desarrollados por los primeros escritores eclesiásticos en relación con la teología patrística y, en resumen, sobre la historia de la salvación, bien hayan sido San Ireneo, Tertuliano y otros, encontraron sus primeros planteamientos y explicaciones en los maestros gnósticos que habían combatido, particularmente en las doctrinas enseñadas por Valentín y sus seguidores. De esta manera y tomando por referencia el desafío que aquellos primeros anticipos de especulación representaron en el campo cristiano, ha sido posible determinar con mayor prufundidad y precisión, por ejemplo, la teología de Ireneo de Lión. En dos obras fundamentales para la investigación patrística de nuestros días: La antropología de San Ireneo (Madrid, 1969) y la posterior Teología de San Ireneo en cuatro volúmenes (Madrid, 1985-1996), este tipo de método crítico-hermenéutico ha confirmado su eficacia. El proceso metódico abarca tanto atender al aspecto que subyace como contexto a los fenómenos estudiados y cuyo acceso supone sólida erudición histórico-filológica y capacidad de interpretación reconstructiva, como la detención en lo que no dicen explícitamente los textos, pero que sugiere la intertextualidad. $\mathrm{O}$ sea, en nuestro caso particular, la atmósfera polémica que se impone al lector, tácita, pero no menos presente, lo que exige identificar la mentalidad del adversario impugnado. Este enfoque metodológico integral, aunque complejo, en tanto que posibilita el manejo de un instrumento de penetración intelectual apto para captar el pensamiento de los primeros grandes autores patrísticos como Justino, Tertuliano, Clemente, Orígenes y particularmente San Ireneo, es el que condujo por necesidad al P. Orbe al estudio previo, amplio, intenso e independiente de los gnósticos, en especial

(1) Cf. E. Romero Pose, "Bibliografía del P. Antonio Orbe", en Epiméleia. Revista de Estudios sobre la Tradición VI, 11/12 (1997), 7-9. 
de los valentinianos, a través de obras mayores y que ahora se han constituido en clásicos, como son los Estudios valentinianos I-V (Roma 1955-1966) y Cristología gnóstica. Introducción a la soteriología de los siglos II y III (Madrid, 1976).

Advertía asimismo el estudioso jesuita, el interés que la filosofía asumía para estos intérpretes gnósticos, superior incluso que para los escritores eclesiásticos y, viceversa, el enojoso relieve que para los filósofos platónicos significaba el aparente uso arbitrario que los susodichos gnósticos hacían de la filosofía de Platón. Nada más que lo comprometiera dijo el crítico investigador jesuita dentro de su imponente producción y hasta solía rehuir específicamente el motivo del reiterado y extenso empleo que los gnósticos hicieron de la filosofía.

Mi tarea, en vista de lo dicho, aspira a ser triple:

$1^{\circ} \quad$ Señalar la importancia que adquiere para la investigación de los orígenes cristianos advertir que ante los ojos de los filósofos gentiles los gnósticos eran identificados como gestores de un pensamiento de naturaleza filosófica.

$2^{\circ} \quad$ Teniendo en cuenta al primero de los apologistas cristianos que hace un uso explícito de la filosofía, Justino de Roma (primera mitad del siglo II), mostrar que este considera preexistentes a ciertos gnósticos que ha conocido y que forman parte de escuelas gnósticas, y el rechazo y condena que hace de ellos y de su forma de filosofar, adoptando una modalidad diferente de filosofía, que considera apta para la enseñanza cristiana.

$3^{\circ}$ Dar a entender, por contraposición, el tipo de pensamiento filosófico que los gnósticos rechazaban, pero al mismo tiempo la filosofía teosófica que tempranamente habían prohijado y practicado, según es posible confirmarlo ahora con el apoyo de los escritos directos de la biblioteca de Nag Hammadi.

Se desarrollarán, en consecuencia, los cuatro acápites siguientes:

I. Los filósofos griegos y los gnósticos.

II. Los gnósticos como adherentes de una filosofía religiosa impracticable cristianamente, según San Justino.

III. Los gnósticos como precursores de la filosofía cristiana.

IV. Conclusiones comparativas.

\section{LOS FILÓSOFOS GRIEGOS Y LOS GNÓSTICOS}

Si comenzamos nuestra revisión de los testimonios gentiles de acuerdo con la cronología en un desplazamiento inverso, de atrás hacia adelante, observamos lo siguiente:

El neoplatónico hierático Jámblico de Calcis cuando escribe en fecha próxima a la primera de sus obras, la conocida con título impropio como Los misterios egipcios, su tratado Sobre el alma, aporta un testimonio inobjetable en apoyo de nuestro fin, porque se trata de un aspecto dentro de un resumen informativo:

"Platón y Pitágoras colocando al frente la naturaleza del alma como sobrenatural y generadora de la naturaleza enseñan que sus actividades son más dignas 
y más venerables que las de la naturaleza. Tampoco la hacen que se origine desde la naturaleza, sino que sostienen que ella dirige desde sí y en sí las propias actividades... Pues bien, incluso ahora entre los platónicos muchos disienten. Unos, como Plotino y Porfirio, congregando en un solo orden y en una sola idea las especies, las partes y las actividades de la vida, y otros, como Numenio, haciéndolas esforzarse en la lucha; otros, como los discípulos de Atico y de Plutarco, poniéndolas de acuerdo a partir de los que se combaten. Estos dicen igualmente que puesto que preexiste a los mivimientos desordenados e irregulares, ellas (=las almas) avanzan para adornarlos y ordenarlos y de este modo combinan el concierto a partir de ambos, siendo causa de las operaciones de los descensos, según Plotino, la alteridad primera, pero según Empédocles, la huida primera de Dios, según Heráclito, el reposo en el cambio, según los gnósticos, un desvarío (paránoia) o una desviación (parékbasis) y según Albino, el juicio errado del libre albedrío" (2).

Si se observa objetivamente, de manera espontánea y natural la información, Jámblico emplaza a los gnósticos en una serie de filósofos que les preceden o que vienen después de ellos en relación con la interpretación de la causa que pone en movimiento los descensos que cumplen las almas. No nos interesa en este momento describir el contenido de la doctrina que encierra la noticia doxográfica, cuanto advertir que Jámblico no discrimina a los gnósticos como no filósofos, sino que los incluye sin mayores explicaciones en una lista de autores filosóficos sin necesidad de aclarar por qué los coloca aquí, o sea, que los admite como filósofos dentro de un grupo de otros bien identificados por ser reconocidos como tales.

Porfirio de Tiro, el discípulo de Plotino, expresa claramente en el capítulo XVI de la biografía que ha dedicado a su maestro, es decir, la Vida de Plotino, entre los veranos de los años 299 y 301 :

"En el tiempo de Plotino existían entre los cristianos muchos otros, y ellos siendo miembros de una corriente de pensamiento inspirada en la filosofía tradicional como discípulos de Adelfio y Aquilino, los que habían adquirido muchos tratados de Alejandro de Libia, de Filocomo, de Demóstrato y de Lydo, mostrando también revelaciones de Zoroastro y de Zostriano, de Nicoteo, del Alógenes, de Meso y de otros semejantes, engañaban totalmente a muchos y ellos mismos se engañaban, pretendiendo que Platón no había penetrado en la profundidad de la sustancia inteligible" (3).

Porfirio en una fecha que puede considerarse bastante próxima a la del escrito que se acaba de tener en cuenta de Jámblico, pero refiriéndose en su noticia a hechos sucedidos hace unos treinta años antes, allá por el año lectivo plotiniano de

(2) De anima 374.14-375.18, J. Estobeo, Anthologium I, ed. C. Wachsmutt-O. Hense, Berlín, 1884. Ver F. García Bazán, en Syllecta Classica 8 (1997), 129ss.

(3) Cf. F. García Bazán, "Los gnósticos y los neoplatónicos posteriores a Plotino: Porfirio, Jámblico y Proclo”, en Epiméleia VI, 11/12 (1997), 83-86. 
265-266, se refiere asimismo a los gnósticos, que son cristianos, pero aficionados a la filosofía, que pretendían poseer su propia "escuela filosófica" (haíresis), una escuela inspirada en la tradición pitagórica en tanto que discípulos de los maestros Adelfio y Aquilino, e inclinados a la lectura y reflexión simultáneas de tratados neopitagóricos y de revelaciones de la propia asociación, entre los que ciertamente no parecían encontrar contradicciones, sino complementaridad. Podían, en cambio, asegurar que el conocimiento que Platón y los que le seguían sostenían de acuerdo con la contemplación intelectiva, sin estar fortalecida por la práctica, era una filosofía disminuida, razón por la cual debía declararse que Platón no había entrado en contacto con la profundidad de la realidad inteligible. Es decir, explicada la afirmación gnósticamente: no había alcanzado una experiencia con el seno divino anterior al Pleroma, el umbral del Padre Perfecto o Uno/Unico.

Pero lo indicado respecto de los gnósticos era una idea fija del obsesivo Porfirio, al punto de que unos años antes de redactar la biografía de su maestro, en Sobre la abstinencia de la carne animal, había registrado y recordado las convicciones de estos gnósticos valentinianos, pero como deficientes filósofos de la ética, igual que los cínicos:

“'Por lo tanto', dicen, 'igualmente nos sucede a nosotros. Si nos guardamos de los alimentos nos hacemos esclavos del pensamiento del temor. Es necesario, sin embargo, que todo se nos someta. Porque si una concentración pequeña de agua recibe alguna suciedad, de inmediato se impurifica y es dominada por la suciedad. Pero el Abismo no se contamina. De esta manera también los alimentos vencen a los pequeños, pero en donde se da un Abismo de poder, todo se recibe y nada impurificada'.

Engañándose de acuerdo con semejantes ideas actuaban engañados y en lugar de un abismo de libertad conduciéndose hacia un abismo de infortunio se han ahogado en él. Esto hizo también a algunos de los cínicos que todo lo ambicionaban, que se ataran estrechamente al responsable de sus errores, al que suelen llamar lo indiferente" (4).

En estos pasajes porfirianos, no solo se hace presente una frase similar a la que se ha leído en V.P. XVI, 7-8, en relación con el autoengaño de pensamiento y acción de los personajes acometidos, sino que asimismo se registra un eco de la enseñanza gnóstico-valentiniana sobre la inutilidad de las purificaciones exteriores, del mismo modo como oportunamente lo denunciará Mani (5). Pero lo que es conveniente poner de relieva en la ocasión es la sencilla razón por la que recurrimos a este texto. Los personajes aquí aludidos y rechazados son pensadores de doctrina equivocada, igual que los cínicos. Proseguimos, pues, moviéndonos dentro de un círculo filosófico según la consideración de los mismos filósofos.

Pero Plotino en el curso escolar de los años 265-266 al que ya nos hemos referido, en la célebre "gran tetralogía" (Enéadas III,8; V,8; V,5 y II,9), clases que

(4) Cf. De abstinentia I, 42, 1-5 y ver García Bazán, ibídem, 87-88.

(5) Cf. Códice Coloniense de Mani 84,10-85,4 y F. García Bazán, Aspectos inusuales de lo sagrado, Madrid, 2000, 167. 
le ocuparon la casi totalidad del año lectivo, protesta y arremete contra estos contertulios que se autodenominan "los que han conocido", porque se expresan de este modo cayendo en la contradicción de hacer un mal empleo de la filosofía. Usan la enseñanza de Platón, pero la entienden torcidamente, la exponen con otras palabras cuyo exótico significado deriva de alguna doctrina bárbara y todavía tienen ánimo e ínfulas para decir que es Platón el que no comprende bien, porque no ha llegado a la "profundidad inteligible". Se tratan para Plotino de miembros de una escuela que pretenden que sea filosófica, buscando justificación estos pretendidos filósofos en libros de doctrina y apocalipsis que están lejos de ser platónicos, como todo el conjunto de su enseñanza; pero que han sido antes sus "cofrades" fílosóficos, a los que ha tenido entre sus oyentes interesados por la filosofía platónica y con los que ha convivido incluso doctrinalmente, hasta que los enfrentamientos intelectuales han agotado a las partes, se ha ido de la polémica al conflicto y de aquí a la enemistad. Me permito ofrecer solo algunos cortos pasajes en relación con lo dicho:

- "Por lo tanto, si se pasara revista a muchos otros puntos e incluso más, a todos, tendría materia suficiente para mostrar caso por caso, cómo es su doctrina. Para nosotros, en verdad, existe una cierta consideración hacia alguno de nuestros amigos, los que habiendo encontrado esta doctrina antes de llegar a ser nuestros cofrades, no sabemos cómo permanecen en ella. Ellos, sin embargo, no dudan al decir ciertamente las cosas que afirman, ya sea porque quieran acreditar como verosímiles sus propias doctrinas, o porque igualmente piensen que son verdaderas. Pero nosotros en tanto que hablamos dirigiéndonos a los íntimos, no a ellos (pues nada llegaría a persuadirlos), para que no sean perturbados por ellos, aun cuando no aportan demostraciones (¿cómo podrían hacerlo?), sino expresándose con arrogancia, hemos dicho estas cosas, siendo otro el modo como de escribir uno se habría defendido contra ellos que osan despedazar lo que está noble y verdaderamente enseñado por varones antiguos y divinos" (6). Facilitamos otras ilustraciones extraídas de un mismo capítulo:

- “Qué, sin embargo, es menester decir acerca de las otras realidades que introducen, moradas en el extranjero, contrafiguras y arrepentimientos? Porque si dicen que estos son afecciones anímicas, cuando estaba en arrepentimiento, y que son contrafiguras, cuando, por decir, contempla imágenes de los seres, pero todavía no lo que es realmente, están usando palabras nuevas para consolidación de la propia escuela filosófica (tes idías hairéseos), en efecto, maquinan esto como si no estuvieran en relación con la antigua lengua griega, aunque los griegos que lo conocían claramente hablaban sin tufos de los ascensos que a partir de la caverna avanzan más y más, progresivamente, hacia una contemplación más verdadera. En general, sí, algunas de estas cosas han sido sacadas de Platón y otras, cuantas innovan para establecer la filosofía propia, esas se encuentran fuera de la verdad... Pero ellos al no entender... se mantienen lejos de saber qué sea el Demiurgo. Asimismo, mienten en cuanto al tema de la creación y en cuanto a muchas otras cosas de Platón, como si ellos

(6) Cf. Enéada II,9 (33), 10 al final (F. García Bazán, Plotino y la gnosis, Buenos Aires, 1982, 244-245). 
hubieran tenido el conocimiento a fondo de la naturaleza inteligible, pero no él ni los demás bienaventurados varones... Ellos, empero, pueden investigar las diferencias de las almas por sus afecciones o como naturaleza, aunque no agraviando a aquellos divinos varones, sino recibiendo sus enseñanzas de buen grado, como de muy antiguos y habiendo tomado de ellos lo que dicen bien sobre la inmortalidad del alma, el cosmos inteligible, el Dios primero, la exigencia de que el alma huya de la familiaridad con el cuerpo, la separación de este y la huida de la generación a la esencia; porque encontrándose estas enseñanzas en Platón en tanto que las digan claramente, hacen muy bien. Si dicen que quieren diferir sobre estas cosas, ningún celo hay de ello”. Sin embargo, sigue advirtiendo claramente Plotino:

- $\quad$ "No es conveniente que confirmen sus propias ideas ante sus oyentes con el agravio y el insulto a los griegos, sino que muestren rectamente las que hay entre ellos, que digan cuantas doctrinas les son propias frente a la doctrina de aquellos, que estableciendo estas doctrinas suyas de buena manera y como corresponde a un filósofo las opongan justamente a aquellos, mirando a la verdad, no persguiendo un buen nombre a partir de la censura contra hombres que han sido juzgados buenos desde antiguo por parte de hombres respetables y que tampoco alardeen de que son mejores que aquellos. Precisamente porque lo que se ha dicho por los antiguos sobre lo inteligible está dicho con mucha más excelencia y saber" (7).

Plotino ha dicho, en síntesis y con mayor indignación, lo que su discípulo Porfirio reitera: los gnósticos son malos filósofos al tratar con su propio estilo los temas filosóficos tradicionales, pero filósofos pese a todo.

De este modo evaluaban los filósofos platónicos del círculo platónico-pitagorizante romano a los gnósticos cristianos, cuando estos movidos por motivos de proselitismo se aproximaron a ellos.

Hay, desde luego, una diferencia notable entre Jámblico, cabeza histórica de los que serán los neoplatónicos seguidores de la teúrgia como remate de la reflexión intelectual, y los neoplatónicos puramente contemplativos, como Porfirio y Plotino. Y no podía ser de otra manera, puesto que, por una parte, Jámblico defiende abiertamente la necesidad de la teúrgia como complemento final de la filosofía teorética, frente a Porfirio, e igualmente respeta en relación con las prácticas teúrgicas la enseñanza del hermetismo egipcio, que a la postre y en su caso particular, le ha sido accesible en tratados teñidos de ideas gnósticas (8).

Pero con anterioridad a Plotino, a Porfirio, a Jámblico, y con una amplitud de miras que excedía al simple helenismo, Numenio de Apamea, el Pitagórico (fl. circa 160), quien entra en contacto con los Oráculos Caldeos y los gnósticos y se deja influir fuertemente por los primeros, se incluye en nuestra cadena de testigos. $\mathrm{Nu}$ menio se inscribe en la tradición platónico-pitagorizante, pero toma como fundamento de su interpretación de la relación Dios-mundo los "tres reyes" o "dioses" de

(7) Cf. Enéada II, 9 (33), 6.

(8) Cf. Epiméleia VI, 11/12 (1997), 100-106. 
la Carta II ${ }^{\mathrm{a}}$ platónica, sin tener en cuenta al Parménides. Sostenedor de un dualismo estricto de principios, Dios y la materia, incluye en su concepción del Dios primero pensado como Intelecto oculto aperceptivo y poder generador indiscriminado, anterior, pero apto para sustentar a un pensamiento creador, ideas que deben más a la concepción caldaica del Intelecto vacío como inteligible y a la Sigé de los gnósticos, sin entrar en ninguno de ambos casos en el análisis triádico interior de la Potencia, que al Bien/Uno, más allá de la esencia y del conocimiento de la rama platónicopitagorizante preplotiniana. Esta vertiente inspirada en una exégesis común del Parménides, admite, sin embargo, que la díada indefinida procede del Uno (Espeusipo, Eudoro de Alejandría, Moderato de Gades). El Dios segundo de Numenio, en cambio, al mismo tiempo autoconocimiento y deseo de generar, posee las características del intelecto paterno caldeo, pero pocos indicios ofrece del Pleroma gnóstico, igual que el Dios tercero que ordena por voluntad del Dios segundo el cosmos, tampoco tiene que ver con los gnósticos. El influjo gnóstico en relación con el Dios primero sí es determinante para nuestro caso y le puede haber llegado a Numenio a través de Basílides, cuya concepción de la "filiedad sutil" dentro de la información más amplia que trasmite Hipólito de Roma de las tres filiedades, es equivalente a la Proténnoia que permanece junto al Padre de los valentinianos y otros testimonios gnósticos directos. Por otra parte, la lectura de la literatura religiosa judía que probablemente Numenio conozca a través de Filón de Alejandría, puede haberle facilitado elementos para su concepción de los planos de la divinidad que interpreta el material filosófico platónico con elementos del Dios judío que es hestós y artesano, según lo había ido moldeando intelectualmente Filón. Por su respeto al judaísmo a través del conocimiento de Filón de Alejandría y de los mismos gnósticos, sus exégesis de Platón en relación con la distinción, relación y subordinación de ambos mundos entrarán a formar parte de la "Preparación Evangélica" que Eusebio de Cesarea completa (9).

De la misma época de Numenio de Apamea es el medioplatónico Celso. Por oposición a su Discurso verdadero, la primera refutación en forma de la doctrina cristiana, mezcla de tratado racional y diatriba, escribirá Orígenes casi setenta y cinco años después, cuando la inclinación eclesiástica heresiológica surgida en Roma más de un siglo antes, esté firmemente establecida en la Iglesia de Alejandría. Y lo que para San Justino, como enseguida veremos, era motivo de apología frente a los acusadores paganos, para Orígenes es dato histórico irrefutable. No es contraproducente, declara Orígenes, que entre los cristianos haya corrientes de pensamiento de diversa profundidad, pero no de doctrinas secretas en sí mismas, sino relativas al vulgo, y es inadmisible confundir a los gnósticos y sus fantasiosas enseñanzas, bien sean de simonianos, basilidianos, valentinianos u ofitas, con la doctrina de los miembros de la Iglesia de la multitud. Por lo tanto, ni diteísmo, ni un mundo perverso poblado de arcontes, ni una separación drástica entre las enseñanzas de los profetas judíos y los cristianos, son enseñanzas que sea lícito afirmar. La antigua tradición protocatólica firmemente asentada desde el momento en que la "buena nueva"

(9) Cf. Oráculos Caldeos con una selección de testimonios de Proclo, Pselo y M. Itálico. Numenio de Apamea, fragmentos y testimonios, trad., int. y notas de F. García Bazán, Madrid, 1991, 213-215. 
se cristalizó como el género evangelio resulta patente y ahora se maneja con esquemas y algunas vacilaciones, pero del mismo modo salta a la vista el anacronismo de la interpretación histórica de los hechos (10).

Llama la atención, empero, que lo que se consideraba nítido para algunos dentro del cristianismo en crecimiento, no lo era tanto para los que lo veían como fenómeno exterior. Pero en los casos citados que proporcionan una imagen extracristiana de los gnósticos, su identificación específica como pensadores indisociables de la filosofía no es puesta en cuestión, al contrario, se parece imponer. La interpretación al respecto de parte de la heresiología (Ireneo, Hipólito de Roma, Clemente, Orígenes, Epifanio), beberá en parte de esta ratificación, aunque con segundas intenciones, cuando acusen a sus adversarios de inspirar su falsa gnosis en la filosofía griega; pero será diferente la imagen que nos proporcionen de ellos, al intercambiar la noción de "filósofo", por la de "hereje", pero ¿en dónde es posible sospechar las raíces del cambio?

\section{LOS GNÓSTICOS COMO ADHERENTES DE UNA FILOSOFÍA IMPRAC- TICABLE CRISTIANAMENTE SEGÚN SAN JUSTINO}

Justino de Roma (convertido al cristianismo circa 133) es el primero de los autores cristianos que aparece oficialmente como habiendo cultivado la filosofía y que ha realizado la tentativa de introducirla legítimamente en el hábito de pensar de los cristianos. Se han escrito obras importantes al respecto (11). No obstante, no estaría de más tratar de determinar la concepción de la filosofía que sostiene, pues se puede observar que en las diversas oportunidades en las que el apologista y mártir se refiere a la filosofía griega, distingue entre sí corrientes e ideas y las evalúa y compara para quedarse, finalmente, con lo que resulta más útil y valioso para su propósito: la enseñanza filosófica de Platón, la que es solo cómoda y realmente superada por la "divina filosofía”, es decir, la filosofía de los profetas y de Jesucristo (12).

Pero cuando San Justino se entrega a esta tarea de reflexión metateórica, al mismo tiempo hace mención al pensamiento de aquellos a quienes llama "herejes", mayoritariamente gnósticos, para condenar sus doctrinas e impedir que se los confunda con los cristianos. Resulta, entonces, lícito preguntarse dentro de este contexto: ¿Se encubren detrás de estas alusiones que desacreditan a los destinatarios, indicios de competencia y rivalidad, o bien solo testimonios de desviación? Ambas cosas a la vez, pues creemos que se trata de una ambigüedad que apunta hacia una doble opción que ha marcado el desarrollo de la historia del cristianismo en sus primeros siglos.

Efectivamente, se puede sospechar que detrás de las diatribas de Justino subyace la tentativa de denigrar una forma de enfocar la filosofía por parte de los

(10) Cf. Orígenes, Contra Celso I,7; III, 12 y V, 29; I, 57; V, 54, V,59-62, VI, 11, VI,24-27. Sobre fechas de obras, cf. H. Crouzel, Origène, París-Namur, 1985, cap. II.

(11) Cf. J.C.M. van Winden, An Early Christian Philosopher, Justin Martyr's Dialogue with Trypho (I-IX), Int., texto y com., Leiden, 1971; M. Marcovich (ed.), Iustini Martyris Dialogus cum Triphone (Patristische Texte und Studien, 47), Berlín-Nueva York, 1997 y ver más abajo n. 13.

(12) Cf. 2 Apología 12, 1-5. 
"herejes" gnósticos, que había precedido y entrado en fricción con el cristianismo que a la sazón se había ido imponiendo entre las cabezas dirigentes de los cristianos de Roma y que en la época de Justino abiertamente se rechazaba.

Efectivamente en las $1^{\text {a }}$ y $2^{\text {a }}$ Apologías (circa 150) anteriores al Diálogo con Trifón (circa 155), Justino afirma dos tesis que permiten comprender su posición respecto de nuestro tema:

$1^{\circ} \quad$ La adhesión que comparte con la tradición cultural judía y que no es una extravagancia cultural para la época, al menos desde el siglo II a. n. e., y que es indisociable de su concepción de la filosofía única, de que la sabiduría oriental y en particular la hebrea es anterior y superior a la griega (13). Los pensadores griegos han aprendido de las doctrinas de Moisés y de esta manera en el campo de la filosofía, ciertos filósofos, no obstante sus debilidades, han llegado a formular algunas nociones que son prefiguraciones de la enseñanza cristiana (14). Este, además, es el sentido de la concepción justiniana de las "semillas del Verbo", que no es de influencia de fondo estoica, sino que adquiere su sentido profundo de la concepción histórica y salvífica cristiana del typos-antítypos o de las parejas complementarias (syzygía) de raíz judeocristiana (15).

$2^{\circ} \quad$ La noticia contundente, además, de que ha escrito: "Una obra (syntagma) contra todas las herejías hasta el presente habidas". Esta afirmación taxativa, aunque desconozcamos el contenido del libro y asimismo carezcamos de información sobre lo que se dice a continuación de él, permite deducir dos conclusiones implícitas: a) que Justino conocía estas "herejías” y que mostraba mayor interés por ellas en tanto que "herejías", que el resto de sus contemporáneos; b) que discriminaba estas corrientes heréticas de la corriente cristiana a la que pertenecía como no cristianas y que abiertamente las condenaba. La razón de su reproche asimismo la ha proporcionado Justino inmediatamente antes. Porque si en relación con la actividad filosófica admite que hay de hecho un género amplio, la "filosofía", dentro del cual entran superficialmente las diversas escuelas filosóficas, aunque difieran y se contradigan en su contenido, el criterio no es rigurosamente válido para el cristianismo. En él, como modelo filosófico, por su orientación hacia la verdad una, las "herejías" son opciones equivocadas y, por lo tanto, no es correcto confundir a los "cristianos" con los "herejes" (16).

Ahora bien, en relación con la postura asumida sobre la filosofía y la herejía, precisa Justino su posición con los siguientes términos en el Diálogo con Trifón:

(13) Ver Eupolemo, Artapano, Josefo y Filón, A. J. Droge, Homer or Moses? Early Christian Interpretations of the History of Culture, Tubinga, 1989, 12-48; Justino, 49-81. Cf. asimismo el cap. I de nuestro libro, El hermetismo, Madrid, Ediciones del Orto (en prensa).

(14) Cf. 1Apol 44,10 (D. Ruíz Bueno, Padres apologistas griegos [s.II], Madrid, 1954, 230); 59,160,7 (247-249); 2Apol 7 (8),1-3 (269); 10, 1-8 (272-273) y 13, 3-5 (276-277).

(15) Sobre el tipo-antitipo y las syzygía, ver Gál 4,22-31; 1Cor 10,1-11, etc. y Pseudoclementinas 15.1-18.18, respectivamente, (F. García Bazán, Aspectos inusuales de lo sagrado, Madrid, 2000, $40-41$ y 165 , n. 9).

(16) Cf. 1 Apol 26, 1-8 (209-210) y 56, 1-4 (245-246). 
"Hay, pues, amigos, y los ha habido, muchos que han enseñado doctrinas y moral atea y blasfema, no obstante presentarse en nombre de Jesús, y son por nosotros llamados del nombre de quien dio origen a cada doctrina y opinión. Y, efectivamente, unos de un modo y otros de otro, enseñan a blasfemar del Hacedor del universo y del Cristo que por Él fue profetizado que había de venir, lo mismo que del Dios de Abrahán, Isaac y Jacob. Nosotros no tenemos comunión ninguna con ellos, pues sabemos que son ateos, impíos, injustos e inicuos, y que, en lugar de dar culto a Jesús, solo de nombre le confiesan. Y se llaman a sí mismos cristianos, a la manera como los gentiles atribuyen el nombre de Dios a obras de sus manos, y toman parte en inicuas y sacrílegas iniciaciones (anómois kai athéois teletaîs). De ellos unos se llaman marcionitas, otros valentinianos, otros basilidianos, otros saturnilianos y otros por otros nombres, llevando cada uno el nombre del fundador de la secta (gnómes), al modo como los que pretenden profesar una filosofía, como al principio advertí, creen deber suyo llevar el nombre del padre de la doctrina que su filosofía profesa" (17).

Del explícito testimonio registrado se puede extraer, por lo tanto, un tercer principio que es aclaratorio y ratificatorio de los otros dos:

$3^{\circ} \quad$ La afirmación de que lo mismo que los gentiles al seguir una escuela determinada dentro del género mayor de la filosofía se inspiran en la enseñanza de un maestro, corrompiendo el sentido filosófico, los herejes siguen igualmente una orientación individual y toman el nombre de una corriente que procede de un maestro: Valentín, Basílides, Saturnilo, etcétera.

Si se tienen en cuenta las interpretaciones acerca de la filosofía que pueden derivar de las nociones descriptas, será posible comprender lo que el mismo Justino escribe sobre la filosofía en su contexto histórico en conversación con el anónimo anciano en Diálogo con Trifón 1-8 y teniendo en cuenta que ya ha optado por la filosofía de Cristo y los profetas. El coloquio ofrece las siguientes notas para el análisis:

$1^{\circ}$ Como intérprete y cultivador de la filosofía gentil Justino ha pertenecido a una de las corrientes de ideas dentro del platonismo que hoy con mayor precisión podemos determinar como de los "platónicos medios". En efecto, el elemento que según él mantiene a la filosofía activa y en unidad es: "la investigación de la verdad". Es decir, el aspecto inquiridor o "zetemático" de la filosofía. Escribe Justino con transparencia: "Ahora, qué sea en definitiva la filosofía y por qué les fue enviada a los hombres, cosa es que se le escapa al vulgo de la gentes; pues en otro caso, siendo como es ella ciencia una, no habría platónicos ni estoicos ni peripatéticos ni teóricos ni pitagóricos. Quiero explicaros por qué ha venido a tener muchas cabezas. El caso fue que a los primeros que a ella se dedicaron y que en su profesión se hicieron famosos, les siguieron otros que ya no hicieron investigación alguna sobre la verdad (toûs epeíta medén exetasántas aletheías péri), sino que llevados de la admiración... solo tuvieron 
por verdad lo que cada uno había aprendido de aquellos; luego trasmitiendo a sus sucesores doctrinas semejantes a las primitivas, cada una tomó el nombre del que fue padre de su doctrina" (18).

Ahora bien, el hincapié puesto sobre el aspecto investigativo de la filosofía es la manera como la Academia Nueva ha interpretado la tradición auténtica de la Academia Antigua, un elemento inspirado en el momento refutativo de la dialéctica de Sócrates y justificativo de la "suspensión del juicio" (epoché), desde que Arcesilao se mudó del Peripatos a la Academia y enfrentó el asentimiento estoico a la percepción sensible de la realidad, base del dogmatismo. La "suspensión del juicio" como ratificación de la auténtica búsqueda de la verdad, evita precipitarse en el dogmatismo y deja genuinamente abierta la posibilidad de la trascendencia platónica. En este sentido Plutarco de Queronea, seguidor del académico Amonio, se autodenomina asimismo "platónico" e igualmente lo hacen otros "medio platónicos", como el autor anónimo del Comentario al Teeteto (19). En estos autores el ingrediente escéptico "no pirrónico" es un factor activo para acercarse a los hechos "mirándolos a fondo" o con atención (sképtomai) (20).

Pero en el pasaje de Justino que se ha transcripto no solo se hace presente lo "zetemático" como propio de la filosofía, sino asimismo la oposición entre la filosofía como "ciencia una" y la multiplicidad de las orientaciones filosóficas. Y es este último aserto el que nos orienta hacia el núcleo de nuestra hipótesis, ya que cuando el interés va dirigido por la "búsqueda de la verdad", según Justino, la filosofía es "ciencia una", que se orienta hacia la verdad, no dirigida exclusivamente por la doctrina de un maestro del que toma el nombre, y el que junto con otros la divide en ramas incompatibles.

El desencuentro de las corrientes filosóficas es un hecho histórico helenístico anterior al siglo I y que se mantiene durante el tiempo de Justino, y son célebres los desencuentros entre estoicos, académicos nuevos y epicúreos (21), igual que entre los platónicos medios y los platónicos pitagorizontes las discusiones sobre el fin de la filosofía como "la semejanza con Dios" (homoíosis theoû) (22). Justino admite asimismo este télos, solo que subordinado al maestro único (23).

(18) Cf. 2, 1-2 (302).

(19) Cf. C. Lévy, "La Nouvelle Académie a-t-elle été antiplatonicienne?", en M. Dixsaut (ed.), Contre Platon 1. Le platonisme dévoile textes réunis par M. Dixsaut, París, 1993, 139-156 y ver F. García Bazán, "Antecedentes, continuidad y proyecciones del neoplatonismo”, en Anuario Filosófico 33 (2000), 111-149 (esp. 116-118).

(20) Cf. J. Opsomer, In Search of the Truth. Academic Tendencies in Middle Platonism, Academia Real de Ciencias, Letras y Bellas Artes de Bélgica, Lovaina, 1998, 9-82.

(21) Cf. Numenio, Sobre el divorcio de los académicos de Platón, en F. García Bazán, Oráculos Caldeos. Numenio de Apamea, fragmentos y testimonios, 254-274; Plutarco, Adversus Colotem. La denuncia del desencuentro de los filósofos se continúa usando por Taciano, Oratio 25,1-2; Atenágoras, Leg 7,2ss; Teófilo de Antioquía, Ad Autolicum III,8-9 y reunidas las diversas formas por Cohortatio ad graecos 4,2ss (M. Marcovich, 6-7), pero ya los gnósticos utilizaban el argumento, cf. TrTrip 109,5ss y EugB 70, 8-16, en A. Piñero, J. Montserrat Torrents, F. García Bazán, Textos gnósticos. Biblioteca de Nag Hammadi I.Tratados filosóficos y cosmológicos, Madrid 1997, 180ss y 468ss.

(22) Cf. Teeteto 176A-B y Eudoro de Alejandría, en Estobeo, Eclogae II,49,8ss, ed. de Wachsmuth; Comentario Anónimo al Teeteto 7, 14-19 (ver J. Opsomer, o.c. 46-49) y más adelante, Plotino, En I, 2 (19),1.

(23) Justino afirma: "No ve el hombre a Dios por su parentesco con él, ni porque posee intelecto, sino porque es templado y justo" (Dial 4,3, p. 308). 
Sin embargo, cuando el apologista cristiano define la filosofía más allá de las notas encomiásticas de los protrépticos (24), no repite las conocidas definiciones nominales de origen académico trasmitidas por las anécdotas de los doxógrafos, ni combina la definición nominal con otras consideraciones de platónicos que confluyen hacia ella, como hace Alcino al comienzo del Didascálico (25), sino que formula una definición más amplia y rigurosamente pitagórica: "la ciencia del ser y del conocimiento de la verdad, y de esta ciencia y sabiduría el premio es la felicidad (epistéme estí tô̂ óntos kai toû alethoûs epígnosis, eudaimonía de taútes tês epistémes kai tês sophías géras)", solo que esta ciencia del ser real, la aplica al conocimiento de Dios, definido como: "Lo que siempre se da del mismo modo e invariablemente y es causa del ser de todo lo demás" (26). Por lo tanto, si Dios "solo es comprensible por el intelecto", las ciencias no llevan a la ciencia de Dios, sino "el intelecto humano adornado por el Espíritu Santo" (27). Por esto, aunque Justino define la filosofía pitagóricamente, sin embargo, rechazó al maestro pitagórico, porque previamente le exigía el aprendizaje de los saberes o ciencias que le permitirían acceder a la sabiduría inteligible (aritmética, música y astronomía -Justino omite en las dos oportunidades a la geometría-), pero estas no representan para él ninguna utilidad de posible ascenso hacia el conocimiento de Dios, como tampoco "el parentesco divino", etcétera, porque como sabemos, es la inspiración del Espíritu Santo la que da unidad y puede elevar sobre la ciencia y verdaderamente operar sobre las virtudes (28).

No obstante, la vía del conocimiento que lleva a la felicidad según el pitagorismo es otra que la señalada como propia del cristiano por Justino, y esa vía está contenida en su definición de la filosofía, de la que Justino ha hecho uso, pero modificándola.

Porque la filosofía es inclinación, propensión y deseo, "amor a la sabiduría", porque la sabiduría es su fin, y la sabiduría es: "la ciencia (epistéme) de los seres que realmente son", o sea, "del ser eterno e inmutable", el verdadero, porque se muestra sin cambio como es. Por ese motivo igualmente las ciencias y su aprendizaje son las puertas de ingreso al ser. En este sentido, las consideraciones sobre la caracterización de la filosofía a que se ha aludido que facilita Alcino, señalan la complejidad que subsiste debajo de las definiciones de los platónicos, pero no nos es de tanta utilidad como la clasificación séxtuple de Amonio de Hermias incluida en los Prolegomena ad Platonicam Philosophiam que señalan mejor hacia lo que los platónicos pitagorizantes admitían por "filosofía" cuando pitagorizaban a fondo. Y es este camino el que nos conduce a la forma como los gnósticos entendían la "filosofía" como "una", un modo que precedió a la tentativa de Justino y que era protocatólicamente inadmisible.

(24) Cf. 2,1;3,3.

(25) Cf. D. Laercio, Vidas y opiniones de los filósofos más ilustres I,12; VIII,8; Cicerón, Cuestiones tusculanas, libro V al comienzo; Jámblico, Vida pitagórica XII, 58-59.

(26) Cf. 4,4-5 (p. 306) en relación con Timeo 27c-28c y ver Atenágoras, Leg 19,1; Cohortatio ad graecos 22 (Marcovich, 53) y F. García Bazán, "Dios Padre como Uno y Ser en los escritos gnósticos de Nag Hammadi. En torno a la metafísica de Exodo 3,14", en Teología y Vida 39 (1998), 325-344

(27) 3,7 y 4,1 (307).

(28) 2,3-5 (303-304) y ver n. anterior. 


\section{LOS GNÓSTICOS COMO PRECURSORES DE LA FILOSOFÍA CRISTIANA}

Jámblico de Calcis define del modo como se ha dicho la filosofía, tanto, por consiguiente, como vía de conocimiento cuanto, simultáneamente, como camino de liberación y realización del alma, al que completan las prácticas teúrgicas (29).

Pero antes que él Moderato de Gades (30), Nicómaco de Gerasa al que Jámblico ha seguido tradicional y estrechamente en su definición (31) y Numenio de Apamea (32), han señalado esta intimidad de la matemática y la sabiduría, su integración mutua en la filosofía como forma de vida y, por lo tanto, la posibilidad de su apertura hacia los ritos colectivos iniciáticos. Esto como hemos recordado con Jámblico se concretó con el neoplatonismo hierático posterior a Plotino, pero había sido anticipado por los gnósticos, como con molestia lo denuncia Justino, y los textos de la biblioteca de Nag Hammadi lo confirman ahora con mayor amplitud.

En primer lugar, los gnósticos rechazan aquel modo de entender la filosofía que ha producido representantes de ella o filósofos como los epicúreos, los estoicos y los mismos platónicos, incluidos entre ellos los neoplatónicos contemplativos.

Este tipo de filosofía se anula a sí misma por la ausencia de unanimidad entre sus miembros y las contradicciones en que caen (Tratado tripartito, Eugnosto, el Bienaventurado, etc.). Estos filósofos no pasan de ser simples hílicos, porque sostienen la eternidad del mundo y, al mismo tiempo, inseguros de su naturaleza, combaten a los psíquicos y a los pneumáticos (33).

Pero en segundo lugar, el lado no refutativo, sino afirmativo. Si nos internamos en los documentos gnósticos que han influido al mismo tiempo al neoplatónico hierático Jámblico de Calcis y al alquimista Zósimo de Panópolis, advertimos que hay un doble modo de entender el conocimiento que es estrictamente paralelo con el de algunos platónicos que pitagorizan.

Declara, en consecuencia la versión gnóstica en copto del Discurso perfecto hermético, (NHC VI,8), el tratado conocido como el Asclepio, en una traducción no esquemática, sino amplia, rica y selectiva, con un contenido simbólico y distinciones conceptuales de que carece la versión latina que también se conserva:

"Si quieres percibir la realidad de este misterio" (o sea, el sentido profundo de la dualidad de sexos en Dios y a su imagen en todos los seres que mantienen la actividad reproductiva universal), "percátate también de la maravillosa imagen que es el coito que se realiza entre el varón y la mujer. Cuando alcanza su

(29) Cf. Int. a la aritmética de Nicómaco 5,20-6,13 y 9, 18-28 (F. Romano, Giamblico, Il numero e il divino, Milán, 1995, 206-209 y 212-213). Más tarde queda consagrada como una caracterización de la filosofía entre las definiciones que se comentan en la Escuela Neoplatónica de Alejandría, por ejemplo, en Amonio de Hermias y David, definición primera: "conocimiento de los seres en tanto que son" (gnôsis tôn ónton hê ónta estín). Ver Prolegómenos a la filosofía platónica (L.G. Westerink, J. Trouillard, A.Ph. Segonds, París, 1990, XLVIIIss).

(30) Cf. F. García Bazán, "Los aportes neoplatónicos de Moderato de Cádiz", en Anales del Seminario de Historia de la Filosofía 15 (1998), 20ss.

(31) Int. a la aritmética I,ii,3 (J. Bertier, Introduction arithmétique, París, 1978, 55).

(32) Cf. fr. 2 (11 L) (F. García Bazán, 234).

(33) 65,15- 66,29. Téngase, presente, además, que Jámblico ha utilizado libros hermético-gnósticos. Ver García Bazán, Syllecta Classica 8 (1997), 144ss y El hermetismo, cap. II. 
plenitud, el semen brota. En este momento la mujer recibe la potencia del varón, y el varón recibe la potencia de la mujer. El semen es el que desencadena esta operación. Por esto el misterio del coito se realiza en secreto, a fin de que la pareja natural no tenga que sentir rubor ante muchos que no comprenden el sentido de esta realidad. Cada uno de los agentes contribuye a la generación. Si el acto tiene lugar ante los que no comprenden su sentido, resulta ridículo e increíble. Se trata, además, de santos misterios de palabras y de acciones, no solo porque no deben oírse, sino también porque no deben verse. Asimismo, la gente de esta especie son blasfemos y carecen de Dios y de piedad. Pero los de la otra especie no son muchos, sino muy pocos, en la medida en que se pueden contar los hombres piadosos. Por lo tanto, sucede que la maldad (-kakía) permanece en muchos cuando carecen de la ciencia (epistéme) de lo que es realmente, porque el conocimiento (gnósis) de lo que realmente es en verdad, es el remedio de las pasiones (páthos) de la materia (hyle). Por esto la ciencia deriva de la gnosis. Pero cuando hay ignorancia tampoco hay ciencia en el alma (psyché) del hombre, las pasiones incurables persisten en ella, y la maldad las acompaña como una herida incurable y esta herida consume al alma y por la maldad ella engendra gusanos y apesta. Pero Dios no es la causa (aitíos) de estos males, porque Él ha enviado a los hombres la gnosis y la ciencia. Oh, Trimegisto ¿Las ha enviado a los hombres solamente? -Sí, oh, Asclepio, a ellos solos las ha enviado" (34).

Hay dos tipos de gnosis, dos formas de conocimiento, inseparables de la auténtica filosofía: la gnosis que otorga la ciencia inteligible y que ilumina el saber del alma: sabiduría y ciencia, episteme inteligible o noética y episteme intelectiva o noérica, pero alcanzada esta, se aspira a otra más libre, la que ahondada o gustada permite la experiencia o contacto con los misterios inefables de la regeneración en Dios.

Se observa, entonces, si tenemos en cuenta la mentalidad rigurosamente conservadora y tradicionalista de los conventículos gnósticos, en la que la hermenéutica oral transmitida grupalmente está por encima de sus expresiones escritas, que el primer contacto y encuentro que los cristianos tuvieron con la filosofía fue de afinidad con el platonismo, pero el pitagorizante, y que en el primer esfuerzo por asimilar cristianamente la filosofía como "filosofía una", se seleccionó lo que espiritualmente le era pariente, porque el origen de la preocupación surgía de la rama de los gnósticos, los que la podían asimilar en su integridad poniendo en acto tres factores que eran propios del cristianismo que profesaban: $1^{\circ}$ precedencia y pureza de la propia tradición, la setiana, instructora también de los magos, de los que aprendió Pitágoras; $2^{\mathbf{o}}$ entendimiento de las diversas corrientes de sabiduría mediante el método de la interpretación espiritual, que al limpiar de lo material y psíquico que separa, está por encima de las divisiones y es universal por la naturaleza de los conocedores y única por su transmisión; $3^{\circ}$ legitimidad intrínseca de su tradición, de la exégesis reservada y de los ritos iniciáticos que la acompañaban garantizados por

(34) Cf. F. García Bazán, Las tres estelas de Set, en Textos gnósticos biblioteca de Nag Hammadi I, 239-251 (2a. ed. 2000, 261-274). 
la continuidad comunitaria reglada por las normas de las asociaciones esotéricas ${ }^{34}$. Lo expresado permite explicar igualmente dos comportamientos opuestos por parte de los gnósticos: que sólidamente preparados los grupos que se dedicaban al proselitismo entre los gentiles, como los valentinianos, trataran de mostrar que las ideas platónico-pitagorizantes que encerraban muchas de sus enseñanzas no obedecían solo a una doctrina más profunda que la de Platón y de Pitagóras, sino que asimismo era más antigua y verdadera, por eso buscaban a los filósofos más afines (los neoplatónicos), generando las conocidas polémicas (35).

\section{CONCLUSIONES COMPARATIVAS}

En síntesis. Para los gnósticos la filosofía es "filosofía cristiana" como conocimiento salvífico y misterio iniciático espiritual y es una, porque ellos son continuidad de las tradiciones secretas de Set. De ella participan y han participado oscuramente otros pueblos y algunos griegos, aunque no todos los que creen haber participado.

Para Justino, en cambio, la filosofía es "filosofía cristiana" y es filosofía una, a la que han precedido como prefiguraciones en el tiempo algunas expresiones de la filosofía griega, por la vía del platonismo y la sabiduría profética del A.T. inspirada por el Espíritu Santo, que es anterior a los griegos y su maestra, inmediata o mediata. La anónima Exhortación a los griegos y Clemente de Alejandría afirmarán lo mismo.

Por esta razón, los filósofos separados de la unidad que siguen a un maestro, no representan a la filosofía, porque a la filosofía la gobierna la "investigación de la verdad" y la verdad es una, bien sea prefigurada o perfecta. Los gnósticos, pues, en tanto que intérpretes "separados" que siguen a un maestro, tampoco representan a la filosofía. Aunque Justino, además, como representante del cristianismo protocatólico, presupone mucho más al enfrentarse a los gnósticos y es explicable que rechazara un modo de adoptar la filosofía como la modalidad gnóstica que orientaba el mensaje del Salvador hacia una corriente de interpretación esotérica precristiana y de prácticas mistéricas que entendían la universalidad por la calidad pneumática del iniciado y no la cantidad de los creyentes y que ofrecía una filosofía religiosa compleja y sistemática, pero plagada de dificultades en su desarrollo para el cristiano ajeno al gnosticismo.

Porque por las pocas ideas que los gnósticos dejaban filtrar, era posible sospechar su peculiar doctrina sobre los principios, su cosmología y su soteriología:

1. Una doctrina sobre los principios, constituida por la afirmación de un Dios uno y trino, pero escindido del Dios creador o demiurgo, y la afirmación paralela de la materia cósmica: masa de elementos sensibles y de pasiones no sensibles,

(35) Cf. F. García Bazán, "Dos breves plegarias gnósticas y su contexto codicológico: Oración de Pablo (NHC I, A*-B*) y Oración de acción de gracias (NHC VI,7)", en La preghiera nel tardo antico. Dalle origini ad Agostino, XXVII Incontro di studiosi dell'antichità cristiana, Roma, 7-9 maggio 1998, Roma, 1999, 67-79. 
identificable con lo malo y originada de la frustración o caída de Sabiduría. Entidad eterna y frontera de la Plenitud.

2. Una cosmología en la que el cosmos se entiende como un universo viviente, dotado de capacidad generativa y movimiento y ordenado providencialmente por el demiurgo, quien ignora lo que está oculto en su plasmación.

3. Una soteriología basada en la premisa de que solo "el que conoce" se salva o libera. Una concepción que implica: a) una gnoseología, b) una antropología, c) una ética y d) una filosofía de la historia.

a) La gnoseología de los gnósticos está resumida en la primera parte del conocido Extracto de Teodoto 78: "No solo es el bautismo el que libera, sino también la gnosis". Gnosis que es pasaje de la ignorancia al conocimiento y gnosis que es conocimiento completo o iniciación espiritual, doblemente: por teoría (el mito o relato gnóstico) y por experiencia, el cumplimiento de las diversas etapas rituales, hasta llegar a la Barbelognosis o recuperación del gnóstico en el Silencio o seno del Padre.

b) En la antropología el eje de la enseñanza es el Salvador, cuya palabra aporta el mensaje de los comienzos (doctrina tradicional setiana). El demiurgo modela el universo y también al hombre según el designio oculto de Sabiduría o Logos, cuyo fin es la recuperación del espíritu en deficiencia, exterior, por lo tanto, al Pleroma. Los aspectos materiales y psíquicos están al servicio del espíritu y el género humano es tripartito: los materiales se condenan con el mundo, que es pasajero e ilusorio, los psíquicos colaboran con el demiurgo y su expectativa cósmica y temporal a la liberación de la totalidad de los pneumáticos; estos, finalmente, se liberan completando la deficiencia espiritual de Sabiduría en la consumación del tiempo.

c) Ética normativa propiamente dicha existe para los psíquicos, que poseen fe y esperanza en el Salvador, que se encarnó, pero cuya segunda venida es trascendente. El gnóstico "conoce". La experiencia y prueba del conocimiento ya la ha tenido con el Salvador psíquico o carnal en el período entre la Resurrección y la Ascensión. El definitivo, empero, se da en cada pneumático cuando se autoconoce desde siempre y para siempre salvado. Hay que conocer para poder resucitar y no al revés. La gnosis no está contra las normas, sino por encima de las normas, que son intrínsecamente simbólicas.

d) Filosofía del tiempo y de la historia. Pero el designio pleromático concentrado en Sabiduría, no se despliega a saltos. La consumación (syntéleia) exige gradualidad. Es un proceso doble de extinción de lo material y psíquico y de liberación de la totalidad del espíritu en deficiencia. La realidad y doctrina de la mediación es inseparable del proceso. El tiempo aprisiona, pero es ilusorio y su esfumación se desplaza con la gradual liberación. Hay de este modo una historia falsa y otra latente, real y verdadera. El Demiurgo, el Salvador y Sabiduría son las instancias mediadoras del proceso inmanente y horizontal, en un caso; trascendente y vertical, en los otros dos.

El Demiurgo, Dios justo, en un todo complejo de luces y de sombras, pero preordenado, en el que rige la justicia distributiva del Logos, es árbitro para el cosmos, y una vez que se iguala el defecto de la luz con el exceso de la tiniebla, 
producida una nada de deficiencia y exceso (justicia conmutativa), deja paso a la obra del Salvador encarnado, quien anticipó y completó la obra de salvación, el proceso dual de la tiniebla que se extingue y la luz que ilumina. Ante tal situación el Demiurgo con su séquito psíquico desaparece, el Salvador con su fructificación completa a Sabiduría y esta reingresa en el Pleroma secreto en el que no será posible la deficiencia (justicia como purificación eterna o "función en sî́). Valiosa esta filosofía completa para sus adherentes como forma de vida universal, aunque confinada entre los grupos pneumáticos y excluyendo a la humanidad genérica, a la sociedad mezclada, a la naturaleza fuente de generación y al mundo, como estructura desmitificada y sus procesos inmanentes, originados en la deficiencia de lo Pleno, como ajenos a Dios, era normal que la corriente cristiana protocatólica inspirada por principios de organización mental antagónicos, la rechazara y excluyera como "herejía", agregándole los cargos peyorativos que provienen de la certidumbre psicológica de que se está en la verdad que respalda el grupo y de la atmósfera polémica que concomitantemente genera. Pero asimismo resultaba natural que los filósofos griegos que platonizaban inspirándose en Pitágoras los rechazaran, puesto que los gnósticos les volteaban varias de sus seguridades no discutibles: $1^{\circ}$ la eternidad del mundo, $2^{\circ}$ la inclusión de la libertad en el lugar inteligible, $3^{\circ}$ lo primero, como Dios uno y distinto, $4^{\circ}$ el origen del mal por efecto de la decisión libre inteligible y, en consecuencia, una ética de inspiración pneumática.

Puede cerrarse, empero, el trabajo subrayando que los ecos de estas polémicas y las dudas que generan no se han agotado, sino que llegan hasta hoy y siguen siendo una auténtico desafío para la investigación como la presencia de una alteridad palpitante del pasado de nuestra historia cristiana, al punto de que S.S. Juan Pablo II ha llegado a escribir en la Encíclica Fides et ratio eufemísticamente de "ciertas reservas" de Ireneo de Lión y Tertuliano hacia los gnósticos, cuando de los mismos pasajes textuales surge que se ha tratado de francas y hasta feroces condenas de los adversarios. Es lícito interpretar que palabras tan benévolas como realistas marcan la actualidad de una temática e incitan a los estudiosos católicos tanto al cultivo de la "ortodoxia", como a la investigación sin trabas de las razones de la "heterodoxia" (36).

\section{RESUMEN}

El artículo, siguiendo el método histórico-crítico y exegético aplicado por A. Orbe a la investigación de la teología patrística, aspira a usar la misma metodología en el estudio de los orígenes de la filosofía cristiana. Se detiene, primeramente, en los momentos de la obra de Justino Mártir (mediados del siglo II), en los que este se refiere simultáneamente a la "herejía" y a cierto tipo de doctrinas y de prácticas ocultas que son atribuibles a los gnósticos. Se determina asimismo la concepción de la filosofía adelantada por Justino como propia de los cristianos, centrada en Logos universal y el recurso a la tipología judeocristiana de las syzygia". Una vez que queda determinada la identidad filosófica que algunos pensadores griegos (Plotino, Porfirio, Jámblico) atribuyen espontáneamente a los gnósticos y con el apoyo de NHC VI,8,

(36) Cf. F. García Bazán, "Encuentro y desencuentro entre fe y razón”, en R. Ferrara y R. Méndez (eds.), Fe y Razón.Comentarios a la Encíclica, Seminario interdisciplinar abril-julio 1999, Buenos Aires, 1999, 53-60. 
65.15-66.29 (fragmento del "Asclepio" en copto), es posible, en cambio, precisar el tipo de filosofía de tendencia platónico-pitagorizante que los gnósticos proponían como el ideal liberador de la metafísica cristiana: una, tradicional y superior a la griega. La orientación protocatólica a la que pertenece Justino y que tiene en él al primer representante de envergadura filosófica, si bien no es ajena a la escuela platónica, reaccionará contra la tentativa de los gnósticos considerada cristianamente incompatible. Se concluye deduciendo que el ensayo de metafisica de los gnósticos ha servido de antecedente histórico e incitación en el interés de los primeros cristianos por conformar una filosofía cristiana rigurosa.

\begin{abstract}
This article looks into the origins of the Christian philosophy, following the historic-critical and exegetic methods applied by A. Orbe to patristic theology investigation. The author takes the work by Justine Martyr (mid II century) in which he refers to the 'heresy' and some covert doctrines and practices which may be ascribed to the Gnostics. The author also determines the conception of philosophy put forward by Justine as belonging to the Christians, which was centred in universal Logos and the resort to the Judeo-Christian typology of the "syzygia". Then the philosophical identity of sorne Greek thinkers, such as Plotinous, Porfirious and Jamblicus is determined, who with the support of the NHC VI,8, 65.15-66.29 (excerpt of the Asclepio in Copt language), attribute it to the Gnostics. However, it is possible to specify the Gnostics' platonicpitagoric philosophical trend, which they propounded as liberation ideal from the Christian metaphysics: One, traditional, and superior to the Greek. The proto-Catholic orientation to which Justine belongs to, and of which Justine is the first representative of a philosophical category, does not ignore the platonic school, and reacts against the Gnostics' claim of making it incompatible with Christianism. The author concludes stating that the Gnostics' metaphysical thesis worked as a historical record and raised interest among the first Christians to make up a rigorous Christian philosophy.
\end{abstract}

